\section{Successive vs simultaneous processing of superimposed visual stimuli*}

\author{
D. L. SCHURMAN, MARK D. EVERSON, and HOWARD A. ROLLINS \\ Emory University, Atlanta, Georgia 30322
}

A visual analogue of Savin's (1967) auditory task was used to examine preferred order of recall and order of recall accuracy for two pairs of visually superimposed digits. Savin (1967) and Rollins, Everson, and Schurman (1972) found that Ss preferred to recall simultaneous auditory information in successive order, even though the information was presented over a single channel. In the present experiments, Ss were found to prefer strongly to recall visual information in simultaneous order. On the other hand, the results of Rollins et al (1972), that Ss are equally accurate when forced to recall simultaneous auditory information in either the preferred or nonpreferred mode, were replicated for this visual task. The results of these experiments, together with the experiment reported by Rollins et al (1972), indicate that verbal information is processed differently by these two sensory systems.

When Ss receive two messages simultaneously, in a single sensory mode, they may elect to process one message and then the other (successive processing) or to collate the two messages and process them both at one time (simultaneous processing).

Savin (1967) investigated the effect of presentation of two simultaneous auditory messages on preferred order of recall. He presented two pairs of simultaneous digits on a stereophonic tape recorder with each digit of a pair recorded on a separate sound track and played back both through a single loudspeaker. Savin found strong S preferences for successive orders of recall. Rollins, Everson, and Schurman (1972) replicated Savin's (1967) results for preferred order of recall. They also used a forced order of recall technique to investigate whether Ss' preferred order of recall was also Ss' most efficient order. The Rollins et al study found that Ss were equally efficient when recalling in either the preferred (successive) or nonpreferred (simultaneous) order. This observed preference for successive orders of recall is unusual, since Ss are reporting the information in an order different from the arrival order-without the channel cues present in the dichotic listening case.

The data of the above studies do not provide evidence which would allow inferences about where, in the processing chain, this preference effect might occur. However, Savin (1967) suggested that such sequential processing effects might be peculiar to the auditory system and independent of input channel effects. One implication of Savin's suggestion is

* This research was supported by McCandless Research Fund Grant No. 4272 to D. L. Schurman and No. 4182 to Howard A. Rollins. that other sensory processing systems may not process simultaneous strings of information in sequential orders. In order to investigate this implication, a visual analogue of the Rollins et al (1972) study was designed. The experiments reported below used two black-on-white digits, superimposed by two channels of a tachistoscope, followed by two more digits similarly superimposed. The rate of presentation was 2 pairs/sec, or faster. Both order of recell preferences and order of recall accuracy were examined.

\section{EXPERIMENT 1} Method

Subjects. Sixteen graduate and undergraduate students from Emory University served as paid volunteer $\mathrm{Ss}$; eight were male. One-half of these Ss were assigned randomly to each of two experimental groups, with the restriction that there be an equal number of each sex in each group. Ss were run individually in sessions lasting about $90 \mathrm{~min}$. presented in a Scientific Prototype Model $800 \mathrm{E}$ t wo-channel tachistoscope. The stimuli were the digits $1-9$, excluding the digit 8 , drawn in black ink on white vinyl cards. These digits were $3 / 4$ in. in height and had a stroke width of $1 / 4$ in. All stimuli were clearly discriminable $(100 \%$ recognition accuracy) when presented at $50 \mathrm{msec}$ duration. Stimuli were centered in the fields of the tachistoscope so that they were superimposed when presented simultaneously. Figure 1 is a pictorial representation of the phenomenal appearance of one digit pair. Dark-adapted conditions were used, and a back-lighted fixation cross was always present $0.5 \mathrm{deg}$ of visual angle below the stimuli.
Apparatus. Visual stimuli were
On each trial, two pairs of superimposed digits were presented for 250 msec each and were separated by a 250-msec dark interstimulus interval (ISI). The presentation of two pairs of digits was accomplished by placing the first set of digits, one to a card, in each channel of the tachistoscope with the second set of digits placed behind the first. After the first flash exposed the first pair to the $S$, the first set of cards was quickly removed during the dark ISI, leaving the second set of cards to be exposed by the second flash. The ISI was timed by a Hunter Model 111C timer, which triggered the tachistoscope again for the second flash. The intervals were calibrated and periodically checked by means of a Tektronix 564B oscilloscope. The 250-msec exposure duration for the stimulus pairs was selected because $250 \mathrm{msec}$ is approximately the average length of time that was required to speak one digit in the Rollins et al (1972) study.

Procedure. Ss were seated facing into the tachistoscope. They were told that they were participating in an experiment on visual perception and memory. Ss were then instructed to focus on the fixation point and, when

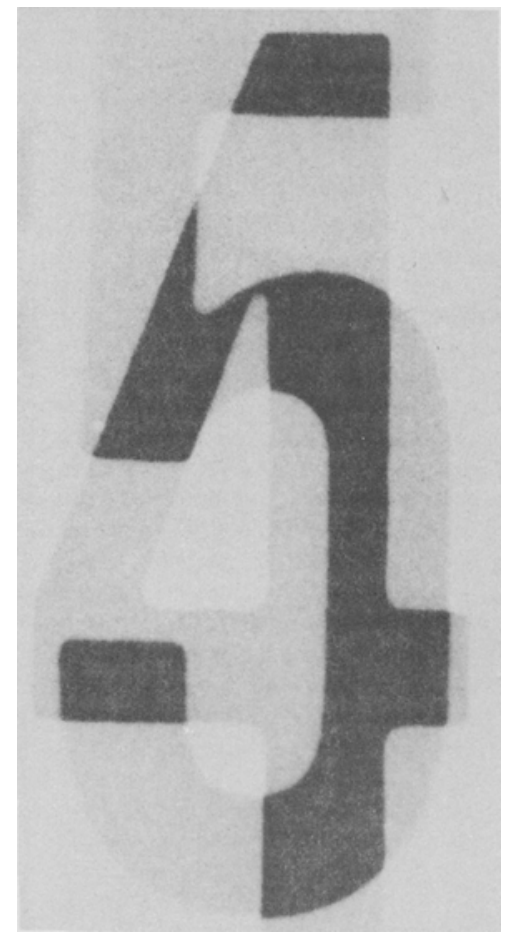

Fig. 1. Pictorial representation of phenomenal appearance of superimposed digit pair. Although the photograph is out of alignment, this was not the case for the actual stimulus presentations. 
Table 1

Mean Pexcent of Trials Correctly Recalled by Order and Condition in Experiment 1 (Average of $12 \mathrm{~S}$ )

\begin{tabular}{lccc} 
& \multicolumn{3}{c}{ Order of Recall } \\
\cline { 2 - 4 } Recall Condition & $\begin{array}{c}\text { Simul- } \\
\text { taneous }\end{array}$ & $\begin{array}{c}\text { Succes- } \\
\text { sive }\end{array}$ & Total \\
\hline Free & $\mathbf{7 5 . 2}$ & 0.2 & $75.4^{*}$ \\
Forced Simultaneous & $\mathbf{8 4 . 4}$ & 0.0 & 84.4 \\
Forced Successive & 2.4 & $\mathbf{8 1 . 1}$ & 83.5 \\
\hline
\end{tabular}

*Percentage of correct trials recalled in simultaneous order was 99.4.
Table 2

Mean Percent of Trials Correctly Recalled by Order and Condition in Bxperiment 2 (Average of 12 Ss)

\begin{tabular}{lccc}
\hline & \multicolumn{3}{c}{ Order of Recall } \\
\cline { 2 - 4 } Recall Condition & $\begin{array}{c}\text { Simul- } \\
\text { taneous }\end{array}$ & $\begin{array}{c}\text { Sucees } \\
\text { aive }\end{array}$ & Total \\
\hline Free & 37.3 & 4.8 & $42.1^{*}$ \\
Forced Simultaneous & $\mathbf{6 2 . 3}$ & 1.2 & 53.5 \\
Forced Successive & 1.2 & 54.4 & $\mathbf{5 5 . 6}$ \\
\hline
\end{tabular}

*Percentage of correct trials recalled in simultaneous order was 89.5. it was sharp and clear, to push the start trigger.

Two Ss from each experimental group were assigned randomly to the control condition. The control condition assersed the possible contribution of masking by luminance summation. Two Ss received 40 trials of single pairs of superimposed digits, then 40 trials of single pairs, followed at a 250-msec ISI by a blank flash of light. The other two Ss received the control trials (flash or no flash) in the opposite order. Control Ss were simply asked to identify the digits.

The remaining 12 Ss were read a standardized set of instructions for the first part of the experiment. These instructions informed them that they would see a sequence of four digits "all within a very short period of time." The first part of the experiment was the free recall condition and was the same for both groups. In this condition, Ss were further instructed to "report all four digits presented, in the order you find easiest, as soon as the last digit has appeared." The experimental session began as soon as Ss had received, and indicated that they understood, the instructions. Six practice trials were presented first. Each practice trial was a particular set of two pairs of superimposed digits which was repeatedly presented until S was able to name all four digits correctly. Any $\mathbf{S}$ who was unable to name correctly all four digits after the ninth repetition was dropped from the study. One $S$ was replaced with another volunteer on this basis. The six practice trials were immediately followed by 40 experimental trials. Each experimental trial was presented only once to each $S$ without feedback. The intertrial interval was 20-30 sec.

A 10-min break was given after the free recall condition. The next two parts of the seasion were the forced recall trials. For the forced recall conditions, Group 1 Ss were instructed to recall the digits in simultaneous order. Simultaneous order would be both digits of the first pair followed by both digits of the second pair. Group 2 Ss were instructed to recall the digits in successive order, i.e., one digit from the first pair followed by one digit from the second pair, followed by the remaining digits from each pair. In addition to the verbal instructions, Ss were shown a visual illustration of a typical trial and the correct order to aid their understanding of the correct order of response. In this first forced recall part of the experiment, Ss were again given 6 practice and 40 experimental trials. In the 6 practice trials, Ss were practiced at recalling the digits in appropriate order.

The third part of the session began after another 10-min break. The instructions for the third part were reversed for the two groups, i.e., Group 1 Ss were now instructed to recall the digits in successive order and the Group 2 Ss to recall the digits in simultaneous order. Visual illustrations were again given to aid understanding of the correct order of recall. Again, 6 practice and 40 experimental trials were presented.

\section{Results}

Two classifications of errors were analyzed. The first class was trial errors-trials in which one or more digits were omitted or reported incorrectly. The other class was order errors-errors in order of report in the forced recall conditions. For the control Ss, mean percent of trials correctly reported was $87.5 \%$ for the single pair alone and $85.6 \%$ for the single pair followed by a 250-msec flash of light. We concluded that no luminance summation occurred for this ISI and exposure duration.

The experimental results are given in Table 1. Only the trials on which one or no gross error, i.e., digits omitted or misrecalled, occurred were used to determine the order of recall preference, since more than one gross error made it impossible to classify order of recall unambiguously. An analysis of variance was performed to examine the effects of sex, groups, and order of recall in the forced recall conditions. All of these $F$ ratios were less than 1 .

As can be seen from Table 1 , the main result was that Ss overwhelmingly prefer to recall these digits in simultaneous order. When forced to use one order or the other, Ss were slightly more accurate when using simultaneous order, but not significantly so $(t=1.06, \quad d f=22$, $p>.10$ ). Too few trials occurred in other than simultaneous order in the free recall condition to make additional analysis feasible. Only $4.2 \%$ of all trials were not recalled in simultaneous order in the free recall condition. Most Ss volunteered the information that, when instructed to use a successive order of recall, they first recalled the digits in simultaneous order, then reordered them.

The Ss' clear preference was to recall simultaneously presented visual material in simultaneous order, in this visual analog of Savin's (1967) task. However, these results are not unambiguously contrary to the proposition that auditory and visual information processing are the same. In attempting to design a visual analogue to the Rollins et al (1972) auditory experiment, we held faithfully to the time intervals as well as the other methods of that study. However, $250 \mathrm{msec}$ was approximately the amount of time required to speak one digit, but it is a relatively long period of time in which to scan a digit visually. It may well be that the time intervals used in this experiment created demand characteristics in which the $S s$ in the free recall condition perceived their task as simultaneous recall of the digits (Madsen, Rollins, \& Senf, 1970). Accordingly, Experiment 2 was designed to overcome this objection.

\section{EXPERIMENT 2} Method

Subjects. Sixteen naive graduate and undergraduate students from Emory University served as paid volunteers; eight were male. Ss were divided into two groups, randomly, with the restriction that there be an equal number of each sex in each group. Ss were run individually in two sessions on consecutive days. Each session lasted approximately $45 \mathrm{~min}$.

Apparatus. Apparatus was the same as that used in Experiment 1.

Procedure. Procedure was the same as that used in Experiment 1, with the following exceptions: the digits were presented for $100 \mathrm{msec}$ of exposure 
duration, maintaining the ISI between digit pairs at $250 \mathrm{msec}$.

\section{Results}

Trials were scored for both trial and order errors as before. Control Ss were $65.0 \%$ accurate with digits presented alone and $61.7 \%$ accurate when the digits were followed by a light flash. The experimental results can be seen in Table 2. As is clear in this table, the percentage of correct trials overall decreased markedly for this shorter stimulus duration. However, in the free recall condition, Ss still overwhelmingly preferred to recall the trials in simultaneous order when they recalled them correctly. There were enough trials with one or fewer gross errors which were recalled in successive order, however, to make additional analysis feasible. A ratio of the number of trials recalled in successive order to the number of trials in simultaneous order was computed, and the correlation coefficient between this ratio and number of incorrect trials was calculated. The correlation was $r=.69$. Thus, Ss choosing the simultaneous order of recall tended to be more accurate in their recall. This result was the reverse of the tendency found by Savin (1967) and Rollins et al (1972) for the analogous auditory task.

Again, there seems to be no masking by luminance summation occurring $(t<1$, df $=6$, for control group). Since the ISI between digits is the same in both Experiments 1 and 2, it seems possible that it is the long ISI that could create the demand characteristic for simultaneous order rather than the longer exposure duration. To test this hypothesis, Experiment 3 was designed to lengthen the exposure duration (to $200 \mathrm{msec}$ ) while shortening the ISI between digit pairs to the minimum possible with our equipment (150 msec). Thus, the total processing time available for the first pair of digits would be the same as in Experiment 2 (350 $\mathrm{msec}$ ), while the exposure duration was closer to that of Experiment 1.

\section{EXPERIMENT 3}

\section{Method}

Subjects. Ss were 16 paid volunteers from the Emory student body; eight were male. Again, Ss were divided randomly into two groups, with the restriction that there be equal numbers of each sex in each group.

Apparatus. Apparatus was the same as that used in Experiments 1 and 2.

Procedure. Procedure was the same as that followed in Experiment 2, with
Table 3

Mean Percent of Trials Correctly Recalled by Order and Condition in Experiment 3 (Average of $12 \mathrm{Ss}$ )

\begin{tabular}{cccc} 
& \multicolumn{3}{c}{ Order of Recall } \\
\cline { 2 - 4 } $\begin{array}{c}\text { Recall } \\
\text { Condition }\end{array}$ & $\begin{array}{c}\text { Simul- } \\
\text { taneous }\end{array}$ & $\begin{array}{c}\text { Succes- } \\
\text { sive }\end{array}$ & Total \\
\hline Free & 48.3 & 5.2 & $53.5 *$ \\
\hline
\end{tabular}

*Percentage of correct trials recalled in simultaneous order was 90.6

the following changes: The stimulus duration was $200 \mathrm{msec}$, with a 150-msec dark ISI between the digit pairs. Only four Ss were run under the forced recall conditions, since there was little or no difference between their performance and the performance of the Ss in Experiments 1 and 2. Due to money and time limitations, the forced recall conditions were dropped for the remainder of the Ss.

\section{Results}

As can be seen in Table 3 , the total correct recall was slightly better than that in Experiment 2 for the free recall condition. This result is consistent with the better recall shown by control Ss, who recalled the single digit pair with $76.9 \%$ accuracy, and the digit pair followed by a light flash with $78.1 \%$ accuracy. In each of the three experiments, the percentage of trials recalled without error can be predicted, almost perfectly, from the percent of single pairs recalled correctly if the errors for the first and second pairs of digits are assumed to be independent.

Again, the overwhelming preference is for simultaneous order of recall, despite the shorter ISI used in this experiment. The correlation between the ratio of successive to simultaneous trials with the total number of trials recalled incorrectly was again $r=.69$. Thus, the major result of each of the three experiments replicates.

\section{DISCUSSION}

The Ss clearly prefer to report simultaneous visual stimuli in simultaneous order, while $S$ preferences are clearly in the opposite direction in the analogous auditory task (Rollins, Everson, \& Schurman, 1972; Savin, 1967). On the other hand, neither this study nor Rollins et al's (1972) found Ss any less accurate when instructed to recall in the nonpreferred order. These results suggest that our Ss are easily able to reorder the digits from the preferred to the nonpreferred order for report, or else that $S s$ can process in either order at will. The data reported here do not allow a distinction between these two hypotheses. However, such a distinction could be made by either increasing the number of simultaneous pairs (thus increasing the memory load for reordering) or by recording time and latency of first response (thus assuming that reordering would require more time).

A number of current information processing and memory models assume that verbal information is routed to some common acoustic memory regardless of input source (e.g., Sperling, 1967; Wickelgren, 1965). That is, the printed word and the spoken word are separately encoded acoustically, then stored in a single memory unit regardless of input source. Wickelgren (1965) presented data which support this assumption. If the assumption is accurate, however, the retrieval of information from this common store would be unlikely to differ as a function of input source (as implied by Yntema \& Trask, 1963).

Thus, a common information storage would imply that the observed difference in preferred order of recall for the auditory and visual systems is produced by modality-specific differences in prestorage processes. Auditory information may be processed in sequential strings, but visual information may be processed in simultaneous chunks. This processing would have to occur prior to storage. This suggestion is consistent with Savin's original hypothesis that sequential processing is a characteristic peculiar to the auditory system.

\section{REFERENCES}

MADSEN, M. C., ROLLINS, H. A. \& SENF, $G$. Variables affecting immediate memory for bisensory stimuli: Eye-ear analogue studies of dichotic listening. Journal of Experimental Psychology, $1970,83,3$ (Part 2).

ROLIINS, $H$. EVERSON, M. D. \& SCHURMAN, D. L. Recall order and recall accuracy for two messages presented simultaneously over a single auditory channel. Perception \& Psychophysics, 1972, 11, 153-155.

SAVIN, H. B. On the successive perception of simultaneous stimuli. Perception \& Psychophysics, 1967, 2, 479-482.

SPERLING, G. Successive approximations to a model for short-term memory. In $A$ F. Sanders (Ed.), Attention and performance. Amsterdam : North-Holland, 1967

WICKELGREN, W. A. Distinctive features and errors in short-term memory for English vowels. Journal of the Acoustical Society of America, 1965, 38, 583-588. YNTEMA, D. B., \& TRASK, F. P. Recall as a search process. Journal of Verbal Learning \& Verbal Behavior, 1963, 2 , 65-74.

(Accepted for publication January 31, 1972.) 